\title{
Should Older Cancer Patients be Tested for Coronavirus-19 Disease Before Treatment: Recommendation of the International Geriatric Radiotherapy Group
}

ISSN: 2578-0093

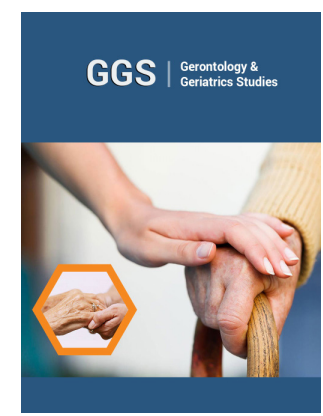

*Corresponding author: Nam P Nguyen, Howard University, Department of Radiation Oncology, Washington DC, USA

Submission: 僵 December 11, 2020

Published: 眥December 16, 2020

Volume 6 - Issue 4

How to cite this article: Nam P Nguyen* Vincent Vinh Hung, Ulf Karlsson. Should Older Cancer Patients be Tested for Coronavirus-19 Disease Before Treatment: Recommendation of the International Geriatric Radiotherapy Group. Gerontol \& Geriatric stud. 6(4). GGS. 000641. 2020. DOI: $10.31031 /$ GGS.2020.06.000641

Copyright@: Nam P Nguyen, This article is distributed under the terms of the Creative Commons Attribution 4.0 International License, which permits unrestricted use and redistribution provided that the original author and source are credited.

\author{
Nam P Nguyen ${ }^{1 *}$, Vincent Vinh Hung ${ }^{2}$ and Ulf Karlsson ${ }^{2,3}$ \\ ${ }^{1}$ Howard University, Department of Radiation Oncology, Washington DC, USA \\ ${ }^{2}$ University of Martinique, Department of Radiation Oncology, Martinique, France \\ ${ }^{3}$ International Geriatric Radiotherapy Group, Department of Radiation Oncology, Washington \\ DC, USA
}

Opinion

During the coronavirus 19 disease (COVID-19) pandemic, older patients are disproportionately affected with a higher death rate compared to younger patients because of the presence of co-morbidity. The likelihood of dying is even higher among older cancer patients who get infected [1]. As COVID-19 patients may be asymptomatic, inadvertent surgery for cancer has been reported [2]. Thus, it raises a serious issue whether older cancer patients should be tested for COVID-19 before any type of treatment such as chemotherapy or radiotherapy which may further depress their immune system and may accelerate their demise. This issue is particularly important as resources of most countries are limited. Older cancer

patients may not be candidates for intensive care unit (ICU) admission and artificial ventilation if the hospital system is overwhelmed with infected patients [3]. As the prevalence of cancer in the US is 8.8 times higher among Americans who are 65-year-old or older compared to younger ones, physicians need to develop a policy on how to manage those patients who are likely to be affected by this pandemic [4]. Currently, the Center for Disease Control and Prevention (CDC) guidelines do not advocate testing for asymptomatic patients because of the shortages of diagnostic testing kits and personal protective equipment (PPE). However, a special case should be considered for older cancer patients to be tested for COVID-19 before considering any type of treatment, not only because of their high mortality risk but also to protect their health care workers (HCW) who may get infected during a routine endoscopic procedure or a surgical operation. Those procedures have been reported to increase the risk of infection through aerosolization of infected droplets which requires a respiratory mask instead of a surgical mask [5]. Deaths of HCW has been reported in many countries secondary to their exposure to infected patients without adequate protection [6]. Inadvertent and prolonged contact with asymptomatic infected cancer patients is one of those situations. As an international organization devoted to the care of older cancer patients who are frequently excluded from clinical trials because of their chronological age (http://www.igrg.org), we believe that older cancer patients should be tested for COVID-19 before treatment [7]. If infected, they should be quarantined and be enrolled in clinical trials for infected COVID-19 patients to test their efficacy and toxicity. In our opinion, it would be more cost effective and potentially lifesaving to perform a diagnostic test than to admit an infected cancer patient after a surgical procedure or following inadvertent chemotherapy. 


\section{References}

1. Zhang L, Zhu F, Xie L, Wang C, Wang J, et al. (2020) Clinical characteristics of COVID-19 infected cancer patients: a retrospective case study of three hospitals within Wuhan, China. Ann Oncol 31(7): 894-901.

2. Tien S, Hu W, Niu L, Liu H, Xu H, et al. (2019) Pulmonary pathology of early phase 2019 novel coronavirus (COVID-19) pneumonia in two patients with lung cancer. J Thorac Oncol 15(5): 700-704.

3. Emanuel EJ, Persad G, Upshur R, Thome B, Parker M, et al. (2020) Fair allocation of scarce medical resources in the time of COVID-19. N Engl J Med 382(21): 2049-2055.

4. Howlader N, Noone AM, Kapcho M, Miller D, Brest A, et al. (2020) SEER cancer statistics reviews, 1975-2017. National Cancer Institute.
5. Tran K, Simon K, Severn M, Silva CLP, Conly J (2012) Aerosol generating procedures and risks of transmission of acute respiratory infections to health care workers: a systematic review. PLoS One 7(4): e35797.

6. Wang J, Zhou M, Liu F (2020) Reasons for health care workers becoming infected with novel coronavirus disease 2019 (COVID-19) in China. J Hosp Inf 105(1): 100-101.

7. Tiberiu P, Karlsson U, Hung V, Trigo L, Thariat J, et al. (2019) Challenges facing radiation oncologists in the management of older cancer patients: consensus of the International Geriatric Radiotherapy Group. Cancers 11(3): 371.

For possible submissions Click below: 